\title{
COPPER CORROSION IN ULTRASOUND CAVITATION FIELD
}

\author{
${ }^{1}$ Cristian Ștefan DUMITRIU, ${ }^{2,{ }^{*}}$ Alina BĂRBULESCU \\ ${ }^{1}$ SC Utilnavorep SA, Constanța, Romania, \\ ${ }^{2}$ Transilvania University of Brașov, Faculty of Civil Engineering, Brașov, Romania \\ e-mail: "cris.dum.stef@gmail.com, alinadumitriu@unitbv.ro
}

\begin{abstract}
This article contains the results of the experiments concerning the mass loss of copper in seawater, in the cavitation presence. The cavitation is produced by ultrasound in an experimental setup designed for this purpose. The models of mass loss are provided and validated by statistical methods. Gravimetric indices are computed, to compare the mass loss in different cases. Differences are noticed in the mass-loss trend at different power of the ultrasound generator.
\end{abstract}

KEYWORDS: cavitation, corrosion, mass loss, gravimetric index, mathematical model

\section{Introduction}

When ultrasound waves pass through a liquid, they exhibit a cyclic succession of expansion and compression phases imparted by mechanical vibrations [1]. During the compression periods, the waves produce a positive pressure that pushes together the liquid molecules. During the expansion periods, the ultrasound waves produce a negative pressure that pulls the molecules apart [2]. At a certain energy level, tiny bubbles (called cavitation bubbles) containing vapours or gases appear [3, 4]. This dynamical process of apparition, development, and collapse of some bubbles or cavities that contain vapours or gases in the liquid mass is called cavitation [5]. The results of these cycles are sonoluminescence, the apparition of oscillations with a frequency that is not the same as that of the ultrasonic field, emulsification and chemical reactions, destruction of parts of solid materials [6-9].

Systematic studies have evolved for many decennia giving different explanations for the damages produced on materials under the action of the cavitation field. Rayleigh [10] was among the first scientists giving them a mechanical explanation, while others considered that these damages were the result of many processes [11-13] of chemical and/or electrical nature $[6,8,14-16]$. Researches proved that plastic deformations appear everywhere in the presence of cavitation, leading to the idea that the chemical action cannot be the primary cause of the destructions produced by cavitation. It seems that the cavitation destructions are the results of the mechanical pressures from the inside of bubbles [5], and erosion is the effect of high-speed jets on the unstable surface of the cavitation bubbles [6].

It is known that various chemical reactions produced under the ultrasound action are related to the cavitation action. Chemical processes induced in the ultrasound field are produced only if the ultrasound intensity is big enough to assure the cavitation apparition and development. From this point of view, one can distinguish between two categories of chemical reactions: accelerated by cavitation and others, produced only simultaneous or after applying a cavitation field and under the action of some factors such as high temperature or high pressure [6]. The corrosion in saline water belongs to the first class.

This article presents the experimental results related to the mass loss of copper in seawater in cavitation field obtained using an experimental setup specially designed for this purpose. Models validated by statistical methods describe the mass loss trend, and gravimetric indices are provided to compare the mass loss at different powers of the generator.

\section{Materials and methods}

\subsection{Experimental setup}

The studied material is $\mathrm{Cu}$, with $99.78 \% \mathrm{Cu}$, $0.0747 \% \quad \mathrm{Zn}, \quad 0.0395 \% \quad \mathrm{Fe}, \quad 0.0446 \% \quad \mathrm{Sn}$. The composition of the seawater used for all the experiments is the following: salinity: $22.17 \mathrm{~g} / \mathrm{L}$ $\mathrm{NaCl}, \mathrm{pH}=7,6.27 \mathrm{meq} / \mathrm{L}$ - total water hardness, $0.051 \mathrm{mg} / \mathrm{L} \mathrm{Fe}, 0.0033 \mathrm{mg} / \mathrm{L} \mathrm{Ni}$. 
The experimental setup used for studying the mass loss in the cavitation field is presented in Fig. 1 $[6,14,15]$. The ultrasound generator operates at 20 $\mathrm{kHz}$ and three power levels: $80 \mathrm{~W}, 120 \mathrm{~W}$, and 180 W. Vessel A (the generator tank) contains a ceramic transducer, with $3.7 \mathrm{~cm}$ diameter, connected to the high-frequency generator that excites the transducer to produce the ultrasound. Vessel $\mathrm{B}$ contains electrodes of electrolytic copper that measure the potential difference appeared between different points at the cavitation zone boundaries.

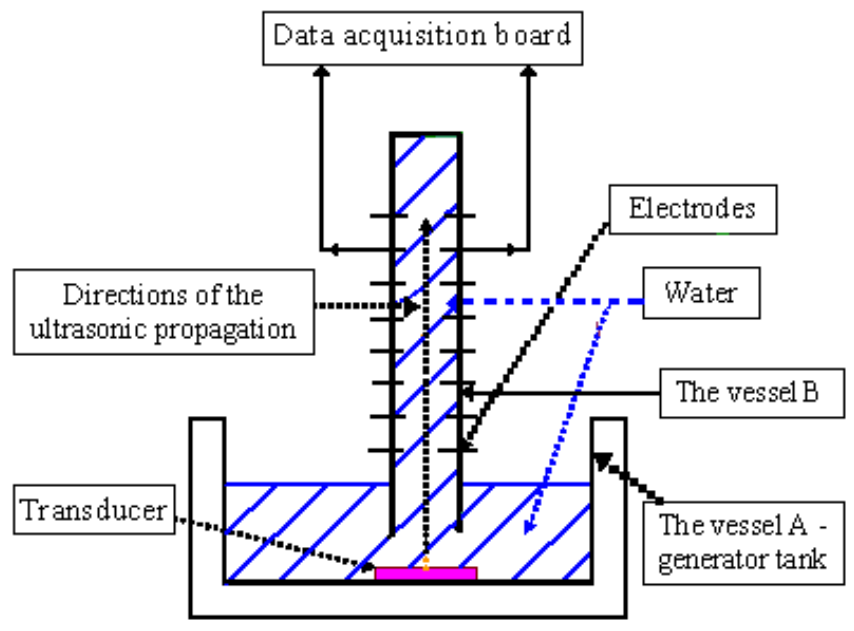

Fig. 1. The experimental set up

The data acquisition board can be connected to different electrodes. It converts analogical signals into a digital sequence and stores the signal in the onboard memory. The PC is then allowed to access the memory and retrieve the data for further processing.

The setup works in the following mode: the liquid is introduced in the bulk and the samples are positioned at the distance of $30 \mathrm{~cm}$ from the transducer. The ultrasound generator is switched on, at one of the power levels. If one wants to study the signal induced by the cavitation bubbles produced by the ultrasonic field, the computer and the software of data acquisition are also switched on. We don't discuss here the last aspect, treated in other work articles [6, 9, 17-22]. We focus on the mass loss of the four samples, in seawater in the presence of cavitation. The working temperature has been kept constant at $20^{\circ} \mathrm{C}$.

The samples have been kept in saline water under cavitation produced by ultrasound for a total of 1320 minutes (380 minutes at $80 \mathrm{~W}, 480$ minutes at $120 \mathrm{~W}$, and 480 minutes at $180 \mathrm{~W}$ of the generator power) and weighted every 20 minutes. All data were put together and the model of the mass loss has been determined.

\subsection{Statistical methods}

The material mass loss and relative mass in the cavitation field have been modelled, and statistical methods have validated the models. The following statistical tests have been used to validate the regression models:

- The determination coefficients $\left(\mathrm{R}^{2}\right)$ and the residuals standard deviation (s) are reported. For a good model, $\mathrm{R}^{2}$ should be close to 1 the standard deviation close to zero.

- The P-P plot and the Anderson-Darling test [23], to check the hypothesis that the residuals in the model are normally distributed.

P-P plot is used for assessing how closely the given data and the theoretical normal distribution are. If the distribution of the tested variable is normal, then the points P-P describe a line superposed with the straight line that represents the theoretical distribution.

In this study, the theoretical confidence intervals at a $95 \%$ confidence level are also provided.

The Anderson-Darling test has been performed at a $5 \%$ significance level. If the p-value associated is less than 0.05 , the normality hypothesis cannot be rejected.

- Testing for the absence of the residuals' correlation by using the autocorrelation function. If the values of the autocorrelation function are inside the confidence interval at the confidence level of $95 \%$, then the residuals are not correlated.

- To check the null hypothesis that the residuals are homoskedastic (they have the same variance), the Bartlett test is used [24] by dividing the residuals series into three groups containing $\mathrm{n}_{1}=11, \mathrm{n}_{2}=\mathrm{n}_{3}=$ 12 values. At a significance level $\alpha=0.05$, if the p- 


\section{THE ANNALS OF “DUNAREA DE JOS” UNIVERSITY OF GALATI \\ FASCICLE IX. METALLURGY AND MATERIALS SCIENCE \\ No. 3 - 2021, ISSN 2668-4748; e-ISSN 2668-4756 \\ Article DOI: https://doi.org/10.35219/mms.2021.3.06}

value corresponding to the test is greater than 0.05 , the homoscedasticity hypothesis cannot be rejected.

The Kruskal-Wallis nonparametric [25] test has been performed to determine whether data series originate from the same distribution. Since the null hypothesis was rejected, the non-parametric Wilcoxon test [26] has been performed to test the same hypothesis for pairs of series.

To quantitatively appreciate the corrosionerosion, the absolute mass variation on the surface (S) has been determined. It is computed by the equation:

$$
\Delta m_{t} / S=\left(m_{1}-m_{t}\right) / S
$$

where $S$ is the sample surface, $m_{l}$ is the initial mass of the sample and $m_{t}$ is the mass at the moment $t$.

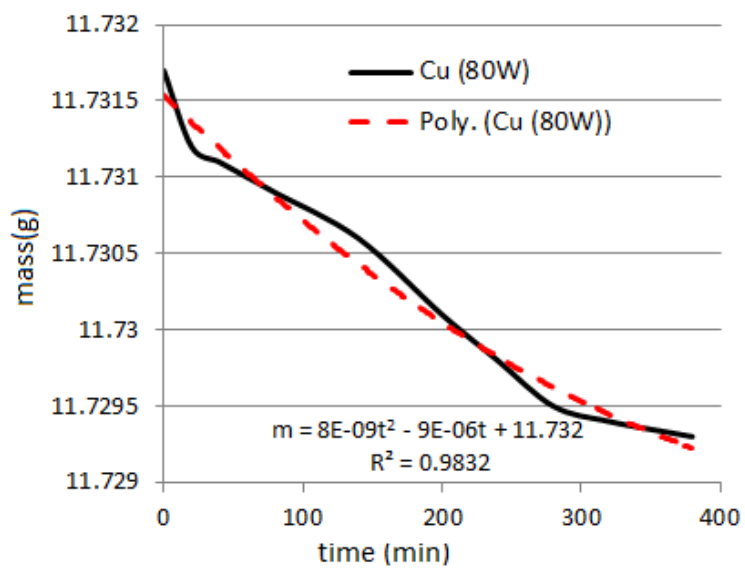

(a)

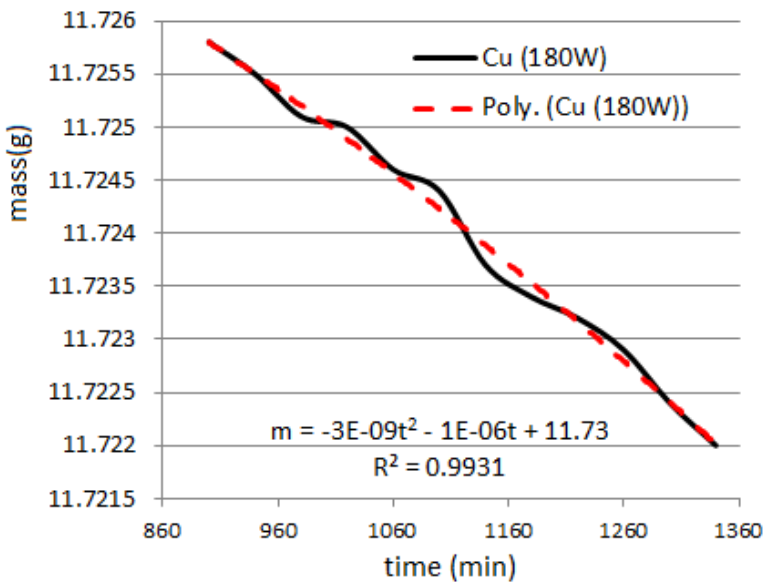

(c)
Finally, the gravimetric index is presented, to assess the mass loss in time per surface.

\section{Results and discussion}

Let us denote by $t$ - the time, $m_{t}$ - the sample mass at the moment $t, s$ - the standard deviation, $\mathrm{R}_{2}$ the determination coefficient, $S$ - the total surface of a sample.

Figures 2 (a-c) present the evolution of the mass loss of the copper sample in time, at each power level of the generator, together with the trends and their equations, while Fig. 2 (d) presents the overall evolution of the mass loss in time of this sample.

From Fig. 2 (a-c) we remark that the trend equations are parabolic and $\mathrm{R}^{2}$ are $0.9832,0.987$ and 0.9931 respectively, so the models describe well mass loss in time.

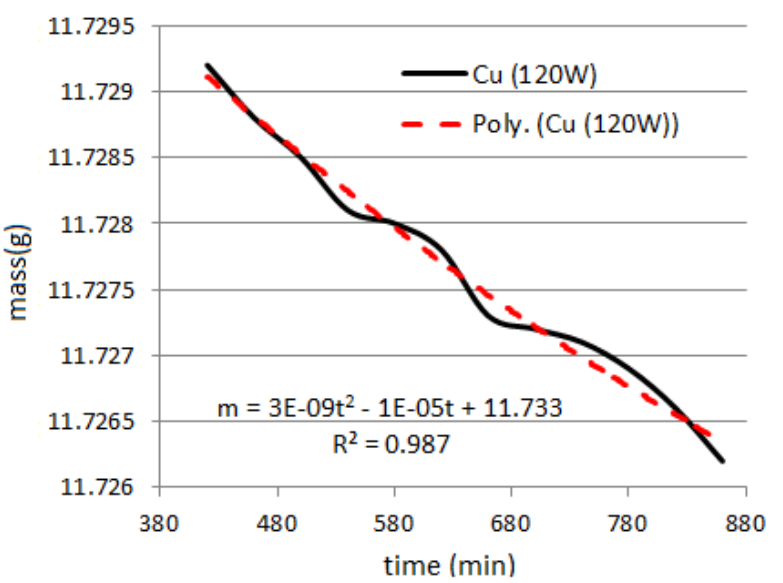

(b)

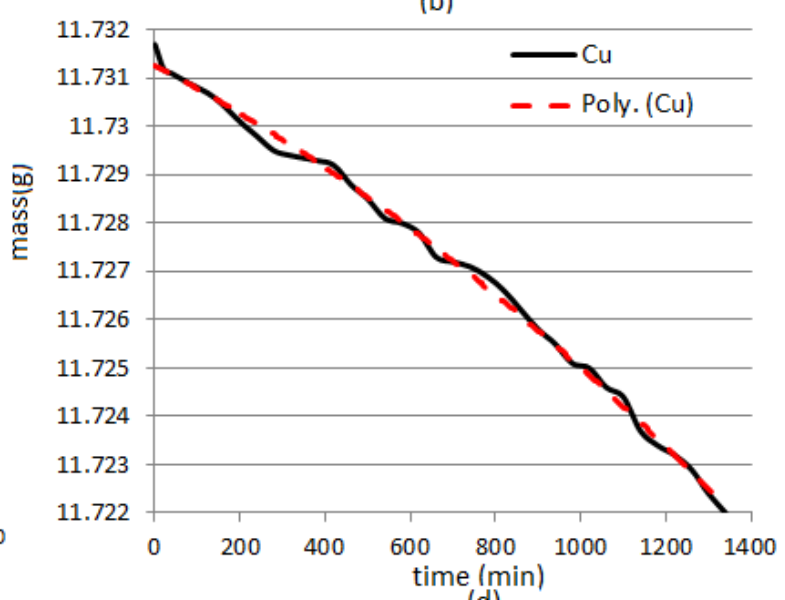

(d)

Fig. 2. The mass variation of Cu sample: (a) at the power of $80 \mathrm{~W}$, (b)at the power of $120 \mathrm{~W}$, (c) at the power at $180 \mathrm{~W},(d)$ during all the experiment. The continuous line represents the record data, and the dotted ones represent the trend 
The equation of the overall mass loss of the $\mathrm{Cu}$ sample is:

$$
m_{t}=11.731265-4.643760 \cdot 10^{-6} t-1.615216 \cdot 10^{-9} t^{2}
$$

with a standard deviation $\mathrm{s}=0.0001637$ and $\mathrm{R}_{2}=$ 0.9968 .

We discuss the residuals of the model (2).

$\mathrm{R} 2$ is very high and $\mathrm{s}$ is very small, so the model is well fitted.

Figure 3(a) presents the P-P plot of the residual in the model (2). Since the observed values (represented by plots) are situated along the straight line (the central one) which represents the theoretical normal distribution, and they are inside the limit of the confidence interval (represented by the exterior continuous line) the hypothesis that the residuals are normally distributed can't be rejected. The value of the Anderson-Darling statistics is $\mathrm{AD}=0.477$, and the corresponding $\mathrm{p}$-value is $0.224>0.05$, so this test cannot reject the hypothesis that the residuals are normally distributed.

Figure 3(b) contains the residuals correlogram, together with the $95 \%$ confidence interval. Since all the values of the autocorrelation function (represented by vertical lines) are inside the confidence interval, the residual autocorrelation can be rejected.

Applying the Bartlett test, the hypothesis that the residuals in the model (2) are homoskedastic cannot be rejected because the p-value $=0.184>$ 0.05 .

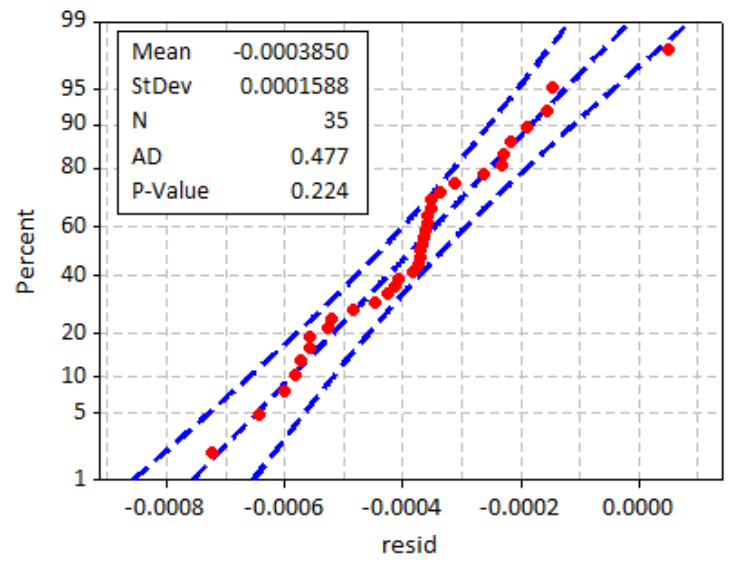

(a)

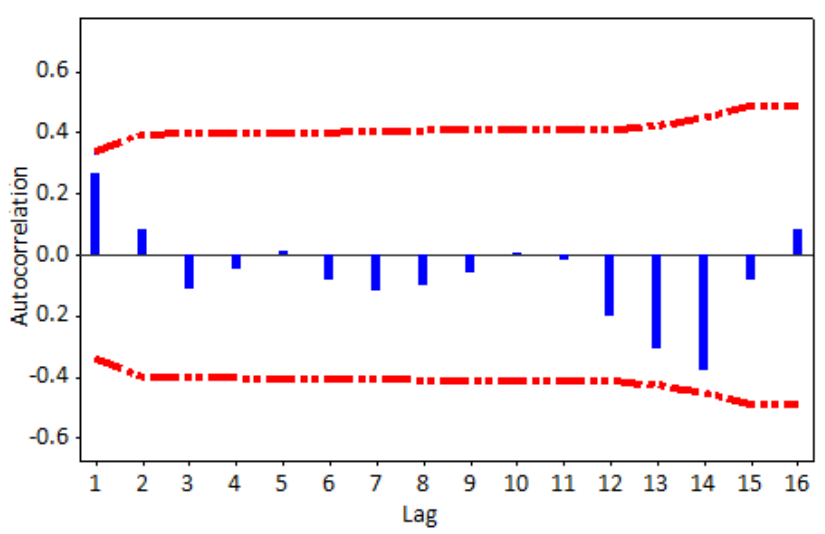

(b)

Fig. 3. (a) $Q-Q$ plot for residuals in the model (1); (b) The correlogram of the residual

The results of the Kruskal-Wallis nonparametric test rejected the null hypothesis $(\mathrm{p}$-val $<0.05)$. After performing the Wilcoxon test, the hypothesis that pairs of series have the same distribution has been rejected as well. This means that the intensity of the corrosion process in seawater depends on the generator power.

To confirm this hypothesis, the absolute mass variations on the surface have been computed for each power level. From Figure 4, it results that the absolute mass loss per surface in time is the lowest when the power was $80 \mathrm{~W}$ and the highest at $180 \mathrm{~W}$. This is confirmed by the total mass loss, in time (Table 1), which is respectively 0.024 (at $80 \mathrm{~W}$ ), $0.0031 \mathrm{~g}$ (at $120 \mathrm{~W}$ ) and $0.042 \mathrm{~g}$ (at $180 \mathrm{~W}$ ).

The gravimetric indices $\left[\mathrm{gm}^{-2} \mathrm{~h}^{-1}\right]$ are computed based on the results from Table 1 . They are: 0.146706 (at $80 \mathrm{~W}), 0.150012 \mathrm{~g}$ (at $120 \mathrm{~W}$ ) and $0.203242 \mathrm{~g}$ (at $180 \mathrm{~W}$ ), and 0.168966 (total). The lowest is the gravimetric index for the first power level and the highest for the third one.

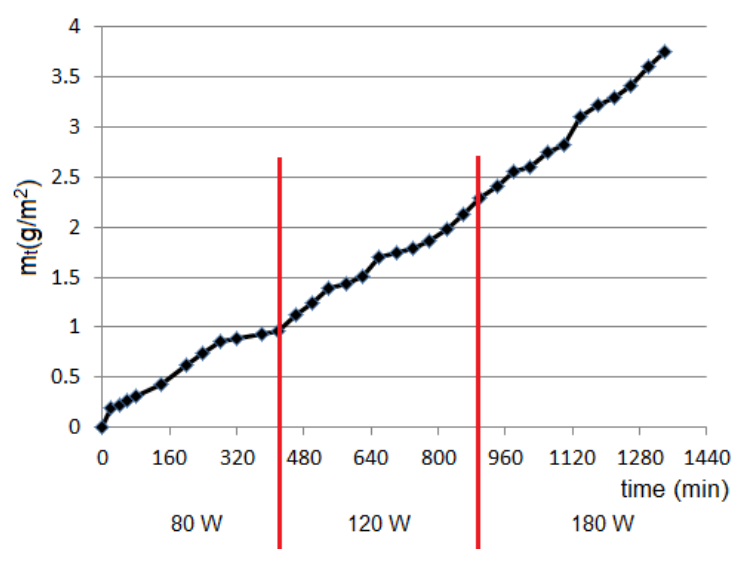

Fig. 4. The absolute mass variations per surface. The vertical red lines delimitate the values obtained at different power of generator 
Table 1. The total mass loss $(\mathrm{g}$ ) in time ( $\mathrm{min}$ ) in seawater in the ultrasonic field

\begin{tabular}{|c|c|c|}
\hline $\begin{array}{c}\text { Power } \\
{[\mathbf{W}]}\end{array}$ & $\begin{array}{c}\text { Time } \\
{[\mathbf{m i n}]}\end{array}$ & $\begin{array}{c}\text { Copper } \\
{[\mathbf{g}]}\end{array}$ \\
\hline 80 & 380 & 0.0024 \\
\hline 120 & 480 & 0.0031 \\
\hline 180 & 480 & 0.0042 \\
\hline
\end{tabular}

\section{Conclusions}

The experiments proved the dependence of the erosion/corrosion speed in seawater on the generator power, increasing with the power level. This finding is in concordance with other studies. Also, it can be shown that the corrosion speed is higher than in freshwater, due to the accentuated chemical corrosion that appears due to the salt content. In the next study we shall present the comparative results of the corrosion-erosion of other copper-based materials in saline water, given the importance of these materials for the naval constructions.

\section{References}

[1]. Tang W. Z., Physicochemical treatment of hazardous wastes, CRC Press, USA, 2003.

[2]. Vajnhandl S., Marechal A. M. L., Ultrasound in textile dyeing and the decolourization/mineralization of textile dyes, Dyes Pigments, vol. 65, p. 89-101, 2005.

[3]. Wu T. Y., et al., Advances in Ultrasound Technology for Environmental Remediation, Springer, Dordrecht, Heidelberg, New York, London, 2013.

[4]. Chen D., Applications of ultrasound in water and wastewater treatment, in: Handbook on application of ultrasound: sonochemistry for sustainability (Eds. D. Chen, S. K. Sharma, A. Mudhoo), CRC Press, Taylor \& Francis Group, Boca Raton, USA, p. 373-406, 2012.

[5]. Anton A., Cavitation, Editura Academiei Române, Bucharest, Romania, 1985.

[6]. Marza V., Contributions to the study of the ultraacoustic cavitation and of some electrical and chemical phenomena induced by it, „Ovidius” University Press, Constanta, Romania, 2003.

[7]. Suslick K., Ultrasound: its Chemical, Physical and Biological Effects, VCH Pub, New York, USA, 1988.

[8]. Roy R. A., Physical aspects of sonoluminescence from A. M. $L$., Ultrasound in textile dyeing and the decolourization/mineralization acoustic cavitation, Ultrason. Sonochem., vol. 1, 1, p. S5-S8, 1994.

[9]. Young F. E., Cavitation, Mac Graw-Hill, Maidenhead, UK, 1989.

[10]. Rayleigh L., On the pressure developed in a liquid during the collapse of a spherical cavity, The London, Edinburgh, and Dublin Philos. Magazine and J. Sci., vol. 34, p. 94-98, 1917.

[11]. Dumitriu C. S., Bărbulescu A., Studies about the copper base alloys used in naval constructions - modeling the loss mass in different media, Sitech, Craiova, 2007.
[12]. Amann T., et al., Analysis of mechanical and chemical mechanisms on cavitation erosion-corrosion of steels in salt water using electrochemical methods, Tribol. Int., vol. 124, p. 238-246, 2018.

[13]. Iwai I., et al., Effects of applied stress on cavitation erosion, Wear, vol. 79 (2), p. 283-293, 1982.

[14]. Bărbulescu A., Marza V., Electrical effect induced at the boundary of an acoustic cavitation zone, Acta Phys. Pol. B, vol. 37(2), p. 507-518, 2006.

[15]. Bărbulescu A., Models of the voltage induced by cavitation in hydrocarbons, Acta Phys. Pol. B, 37 (10), p. 2919-2931, 2006.

[16]. Bărbulescu A., Toncu C., Orac L., Analysis and models of some composites corrosion evolution, Recent Advances in Materials Science, p. 63-69, 2008.

[17]. Bărbulescu A., Marza V., Dumitriu C. S., Installation and method for measuring and determining the effects produced by cavitation in ultrasound field in stationary and circulating media, Patent no RO 123086-B1, 30.09.2010.

[18]. Bărbulescu A., Dumitriu C. S., Mathematical aspects of the study of the cavitation in liquids, in Series on Mathematical Modelling of Environmental and Life Sciences Problems, Proceedings of the 4th Workshop, Constanța, Romania, S. Ion, G. Marinoshi, C. Popa (eds.), Ed. Academiei Române, București, p. 715, Sept. 2005.

[19]. Bărbulescu, A. Dumitriu C. S., Models of the mass loss of some copper alloys, Chem. Bull. Politehnica University (Timişoara), vol. 52 (66), 1-2, p. 120-123, 2007.

[20]. Dumitriu C. S,., Dragomir F., Modeling the signals collected in cavitation field by stochastic and Artificial intelligence methods, $13^{\text {th }}$ International Conference on Electronics, Computers and Artificial Intelligence (ECAI), 01-03 July, Pitești, Romania, p. 1-4, doi: 10.1109/ECAI52376.2021.9515016, 2021.

[21]. Bărbulescu A., Dumitriu C. S., ARIMA and Wavelet-ARIMA Models for the Signal Produced by Ultrasound in Diesel, ICSTCC, Iasi (accepted), 2021.

[22]. Bărbulescu A., Dumitriu C. S., Assessing the Fractal Characteristics of Signals in Ultrasound Cavitation, ICSTCC, Iasi (accepted), 2021.

[23]. Anderson T. W., Darling D. A., Asymptotic theory of certain "goodness-of-fit" criteria based on stochastic processes, Ann. Math. Stat., vol. 23, p. 193-212, doi:10.1214/aoms/1177729437, 1952.

[24]. Bartlett M. S., Properties of sufficiency and statistical tests, Proc. Royal Stat. Soc. A, vol. 160, p. 268-282, 1932.

[25]. Kruskal W. H., Wallis W. A., Use of ranks in one-criterion variance analysis, J. Am. Stat. Assoc., vol. 47 (260), p. 583-621, doi:10.1080/01621459.1952.10483441, 1952.

[26]. Mann H. B., Whitney D. R., On a Test of Whether one of Two Random Variables is Stochastically Larger than the Other, Ann. Math. Stat., vol. 18 (1), p. 50-60. doi:10.1214/aoms/1177730491, 1947. 